\title{
The effect of DL-7-azatryptophan on heterocyst development in the cyanobacterium Anabaena cylindrica
}

\author{
DAVID G. ADAMS* \\ Department of Microbiology, University of Leeds, Leeds LS2 9JT, UK
}

(Received 30 October 1991; accepted 4 November 1991)

\begin{abstract}
Addition of the amino acid analogue DL-7-azatryptophan (AT) to dinitrogen-fixing cultures of the cyanobacterium Anabaena cylindrica, and to cultures in which heterocyst development was induced by the removal of fixed nitrogen from the medium, resulted in the development of many adjacent (double) heterocysts. Cell division in $A$. cylindrica was asymmetrical, with a maximum of $10 \%$ of all cell divisions producing two daughter cells of equal size. During incubation with AT the frequency of symmetrical cell divisions remained unchanged, indicating that the preponderance of double heterocysts induced by the analogue did not result from any change in the symmetry of cell division. Incubation of cultures with AT resulted in a decrease in the number of vegetative cells between heterocysts (the interheterocyst interval). The extent of the decrease was proportional to the length of the incubation period in the presence of AT. Double heterocysts, which constitute a zero interval, developed at a time when the minimum interval was three cells in dinitrogen-fixing cultures, or nine cells in cultures induced to differentiate by the removal of fixed nitrogen from the medium. These observations have been used to formulate a model to explain the influence of AT on the control of heterocyst development and spacing. In this model the inactive form of an inhibitor of heterocyst development is produced constitutively by vegetative cells and is activated either by a co-inhibitor derived from developing or mature heterocysts, or by high concentrations of fixed nitrogen.
\end{abstract}

\section{Introduction}

Filamentous cyanobacteria grown in the presence of a source of assimilable fixed nitrogen consist of undifferentiated vegetative cells. Following transfer to medium free of the nitrogen source, many species develop specialized cells known as heterocysts at regular intervals with each filament. These are the sites of aerobic dinitrogen fixation (see Adams \& Carr, 1981a). The mechanisms by which this one-dimensional pattern of heterocysts is established and maintained are not known, although a model originally suggested by Fogg (1949) still forms the basis of most theoretical explanations. Fogg (1944) noted that heterocyst frequency in Anabaena cylindrica was inversely related to the concentration of intracellular combined nitrogen. He later concluded that the formation of a heterocyst from a vegetative cell occurred when "the concentration within it of a specific

\footnotetext{
* Tel. (0532) 335588; fax (0532) 335638.

Abbreviations: AT, DL-7-azatryptophan; $\mathrm{A}_{2}$, Allen and Arnon's growth medium; $\mathrm{A}_{2} \mathrm{~N}_{4}$, Allen and Arnon's growth medium supplemented with 4 mM-ammonium chloride; $I$, the inactive form of an inhibitor of heterocyst development; $\mathrm{H}$, a co-inhibitor required to activate $\mathrm{I}$.
}

nitrogenous inhibitory substance, probably ammonia or some simple derivative of ammonia, falls below a critical level' (Fogg, 1949). Wolk (1967) suggested that heterocysts were the source of this inhibitor which prevented neighbouring cells from differentiating. Diffusion of this compound away from the heterocyst and its loss from, or degradation within, vegetative cells would establish a decreasing gradient and a vegetative cell could only differentiate if the concentration of inhibitor within it fell below a threshold level (Wolk, 1975, 1989). Wilcox and co-workers extended this basic model to include competition between 'candidates' for differentiation, having noted that cell division was asymmetrical in Anabaena catenula and that heterocysts could develop from only the smaller daughter cells (Wilcox et al., 1973).

An important technique for the elucidation of the mechanisms involved in cellular development and pattern regulation has been to induce specific modifications in the process. Genetic manipulation has been commonly used for this purpose and although mutants of cyanobacteria with altered heterocyst patterns are known (see Adams \& Carr, 1981a), they have so far contributed little to our understanding of the process. In cyanobacteria, however, there is an alternative ap- 
proach. The amino acid analogue DL-7-azatryptophan (AT) has been shown to induce a clear and highly specific modification of heterocyst frequency and the formation of adjacent (multiple) heterocysts (Mitchison \& Wilcox, 1973; Bothe \& Eisbrenner, 1977). In this paper I discuss the effects of this analogue on differentation in $A$. cylindrica and its possible mode(s) of action.

\section{Methods}

Organism and growth conditions. Anabaena cylindrica (PCC 7122, Pasteur Culture Collection of Cyanobacteria) was grown on the medium of Allen \& Arnon (1955) containing $4 \mathrm{mM}$-ammonium chloride $\left(\mathrm{A}_{2} \mathrm{~N}_{4}\right.$ medium) in 1-litre glass culture vessels (Quickfit) at $29^{\circ} \mathrm{C}$. Cultures were kept in suspension by magnetic stirring and gassed with sterile $5 \%(\mathrm{v} / \mathrm{v}) \mathrm{CO}_{2}$ in air. For the simultaneous incubation of large numbers of samples, $30 \mathrm{ml}$ volumes taken from 1 -litre cultures were transferred to sterile boiling tubes, gassed with $5 \% \mathrm{CO}_{2}$ in air and maintained at $29^{\circ} \mathrm{C}$. Removal of ammonium chloride from cultures was achieved by centrifugation and resuspension of filaments in medium lacking $\mathrm{NH}_{4} \mathrm{Cl}\left(\mathrm{A}_{2}\right.$ medium) as described previously (Adams \& Carr, 1989). In all cases the time at which cells were resuspended in $\mathrm{A}_{2}$ was taken as zero hours. The light intensity for growth was $45 \mu \mathrm{mol}$ $\mathrm{m}^{-2} \mathrm{~s}^{-1}$ measured at the surface of the boiling tubes and the centre of an empty 1-litre culture vessel.

Estimation of cell frequencies. Cell division was estimated at a magnification of 2500 and a cell was regarded as being 'in division' if an incompletely formed septum was visible. A division was counted as symmetrical if the two daughter cells could not be said with certainty to be of different size. The frequency of cells in division is expressed as a percentage of total cells, and the frequency of symmetrical cell divisions as a percentage of cells in division.

Heterocyst frequency was counted at a magnification of 600 , a minimum of 1000 vegetative cells being counted for each determination. A cell was counted as a mature heterocyst if it was larger, more regular in shape and the cytoplasm less granular than a vegetative cell and possessed thickened cell walls and refractile polar granules at each end of the cell. A cell was counted as a proheterocyst if it possessed the above properties, but lacked the thickened wall and polar granules of the mature heterocyst. Double proheterocysts or double heterocysts are pairs of adjacent proheterocysts or heterocysts respectively.

Heterocyst or proheterocyst frequencies are expressed as a percentage of total cells. For the purpose of calculating the frequency of double heterocysts and double proheterocysts each double was regarded as a single unit and its frequency expressed as a percentage of total cells.

Effects of $A T$. The effects of AT on cell division and heterocyst differentiation were examined in a number of ways. The simplest experiments involved the addition of AT (final concentration $5 \times 10^{-5}$ M) to 1-litre cultures growing on either $A_{2} N_{4}$ or $A_{2}$ medium. $A$ modification of this was to resuspend a 1-litre $A_{2} N_{4}$-grown culture in $\mathrm{A}_{2}$ and immediately add AT (final concentration $5 \times 10^{-5} \mathrm{M}$ ) to a $30 \mathrm{ml}$ sample in a boiling tube. A more complex experiment involved incubation with $\mathrm{AT}$ for different periods during heterocyst differentiation. A 1-litre culture grown on $A_{2} N_{4}$ medium was transferred to $A_{2}$ and $30 \mathrm{ml}$ subsamples placed in boiling tubes as described above. A final concentration of $2.5 \times 10^{-5} \mathrm{M}$-AT was then added at a different time to each of the tubes and heterocyst frequencies in each sample were counted $34 \mathrm{~h}$ after ammonium removal.

All chemicals were of analytical grade. AT (Sigma) was filtersterilized prior to addition to cultures.

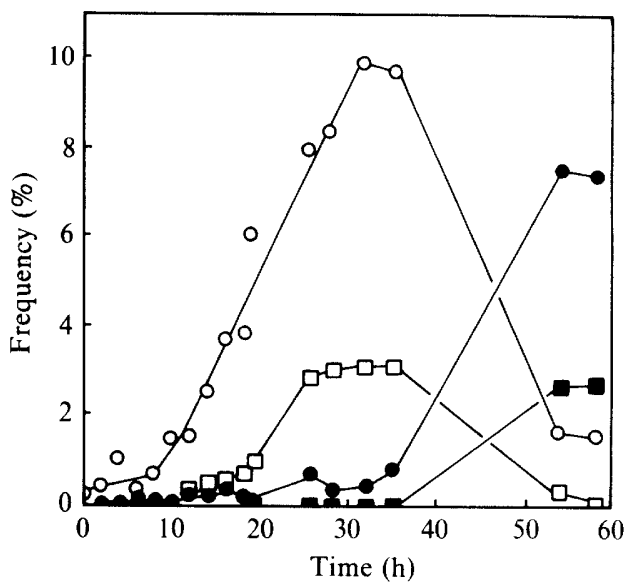

Fig. 1. Effect of AT on heterocyst development in A. cylindrica. A 1-litre culture growing on $A_{2} N_{4}$ medium was transferred to $A_{2}(0 \mathrm{~h})$ and AT (final concentration $5 \times 10^{-5} \mathrm{M}$ ) was added immediately. The frequencies of proheterocysts $(O)$, heterocysts $(O)$, double proheterocysts $(\square)$ and double heterocysts $(\square)$ were estimated at the times indicated

\section{Results}

In accord with previous work (Mitchison \& Wilcox, 1973), the presence of AT during heterocyst development in Anabaena cylindrica resulted in both an increase in heterocyst frequency and the presence of adjacent (multiple) heterocysts (Fig. 1; this can be compared with a typical control culture such as that in Fig. $3 a$ ). Under the conditions employed here the multiple heterocysts were almost exclusively in the double form (Fig. 1). Multiple heterocysts were never seen in untreated control cultures. The frequency of both heterocysts and multiple heterocysts increased with the length of the incubation period with AT following ammonium removal (data not shown).

\section{Effect of $A T$ on cell division}

To test the possibility that an increase in symmetrical cell divisions (Adams \& Carr, 1981 b) could explain the development of double heterocysts following incubation with AT, I examined the effect of the analogue on cell division, under several growth regimes. The addition of AT (final concentration $5 \times 10^{-5} \mathrm{M}$ ) to A. cylindrica grown on $\mathrm{A}_{2}$ medium resulted in a decline in the number of cells in division to approximately $50 \%$ of the control value after $20 \mathrm{~h}$ (Fig. $2 a$ ). However, there was no change in the frequency of equal (symmetrical) cell divisions when expressed as a proportion of cells in division (Fig. $2 a$ ). The percentage of proheterocysts increased rapidly following AT addition while that of heterocysts declined, reaching a stable value by approximately $20-25 \mathrm{~h}$, the point at which the frequency of cells in division also 


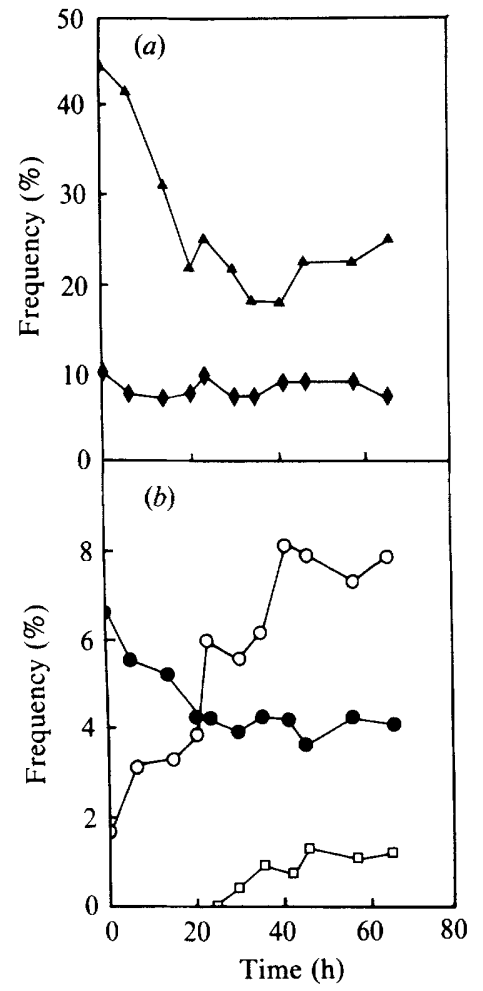

Fig. 2. Effect of AT on cell division in dinitrogen-fixing $A$. cylindrica. AT (final concentration $5 \times 10^{-5} \mathrm{M}$ ) was added $(0 \mathrm{~h})$ to a 1-litre culture growing on $\mathrm{A}_{2}$ medium. The frequency of cells in division $(\boldsymbol{A})$, symmetrical cell divisions $(\bullet)$, proheterocysts $(O)$, double proheterocysts $(\square)$, and heterocysts $(\odot)$, was estimated at the times indicated.

stabilized. Double proheterocysts were first detected at about the same time (Fig. $2 b$ ). When $50 \mu \mathrm{M}$-AT was added to $A$. cylindrica grown in $\mathrm{A}_{2} \mathrm{~N}_{4}$ medium, and therefore lacking heterocysts, there was a steady decline in the number of cells in division to approximately $50 \%$ of the control value after $36 \mathrm{~h}$, although there was no change in the frequency of equal cell divisions (data not shown).

A more complex system involved the addition of AT immediately following ammonium removal. The ATtreated culture (Fig. $3 b$ ) developed a much higher frequency of proheterocysts than the control (Fig. $3 a$ ), although few of these became mature heterocysts. Double proheterocysts were first detected approximately $10 \mathrm{~h}$ after the first proheterocysts developed (Fig. $3 b$ ). In the control culture, the frequency of cells in division remained at about the same level until the first proheterocysts were detected, when it declined rapidly from approximately $50 \%$ to $30 \%$ (Fig. 4). This level was maintained until heterocyst frequency reached a peak, when it rapidly returned to the original value. At no stage did the frequency of equal cell divisions alter. In the ATtreated culture, the percentage of cells in division began to decline immediately and to a much lower level than the control (Fig. 4). There was subsequently only partial

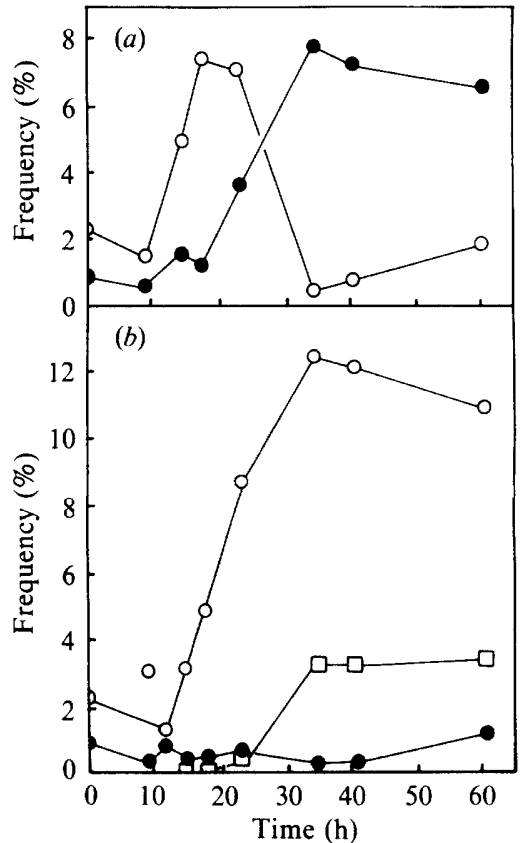

Fig. 3. Effect of AT on heterocyst development in A. cylindrica. Two $30 \mathrm{ml}$ aliquots of a culture grown on $\mathrm{A}_{2} \mathrm{~N}_{4}$ medium were resuspended in $A_{2}$ medium $(0 \mathrm{~h})$ and incubated in boiling tubes. To one $(b)$ was immediately added AT (final concentration $5 \times 10^{-5} \mathrm{M}$ ), the other $(a)$ serving as a control. The frequency of proheterocysts $(O)$, heterocysts (๑) and double proheterocysts ( $\square$ ) was estimated at the times indicated.

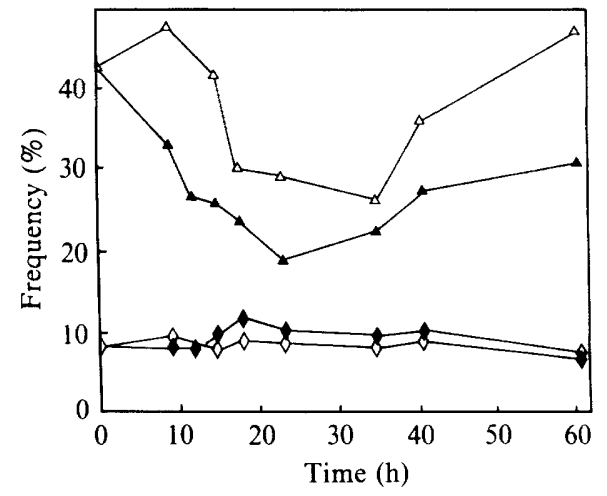

Fig. 4. Effect of AT on cell division in A. cylindrica following the removal of fixed nitrogen. The data shown here were derived from the same two cultures as illustrated in Fig. 3. The frequency of cells in division in the control $(\triangle)$ and AT-treated $(\Delta)$ cultures and the frequency of symmetrical cell divisions in the control $(\diamond)$, and AT. treated cultures $(\bullet)$ was estimated at the times indicated.

recovery and no alteration in the frequency of equal cell divisions was found.

\section{Timing of the AT effect}

Addition of AT immediately following ammonium removal resulted in the development of a high frequency of double proheterocysts (Fig. 5). Some inhibition of 


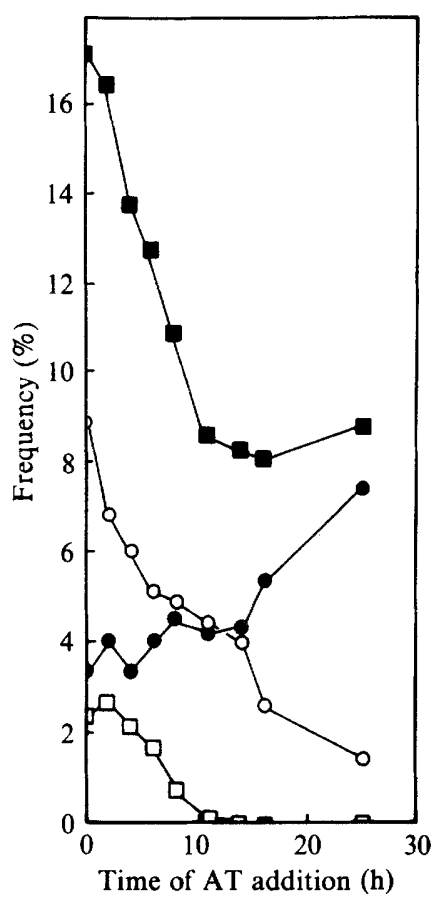

Fig. 5. Effect of AT at different periods during heterocyst development in $A$. cylindrica. A 1-litre culture grown on $\mathrm{A}_{2} \mathbf{N}_{4}$ medium was resuspended in $A_{2}(0 \mathrm{~h})$ and aliquots $(30 \mathrm{ml})$ incubated in boiling tubes. Each time point represents a single tube to which AT (final concentration $\left.2.5 \times 10^{-5} \mathrm{M}\right)$ was added at the time indicated. The frequency of proheterocysts $(O)$, double proheterocysts $(\square)$, heterocysts (O), and the sum of these three ( $\square$ ) was estimated in all of the samples $34 \mathrm{~h}$ after resuspension in $\mathrm{A}_{2}$ medium.

proheterocyst maturation occurred since proheterocyst frequency was higher, and heterocyst frequency lower, than in the control. Total heterocyst frequency was increased twofold. AT had the greatest influence when present during the early stages of proheterocyst formation since, as the time of its addition after ammonium deprivation was increased, the resulting double proheterocyst frequency declined, as did that of proheterocysts. Addition of AT at $11 \mathrm{~h}$ no longer induced double heterocyst formation, nor had any effect on total heterocyst frequency, although maturation of proheterocysts was still reduced. This corresponds to the time at which the maximum proheterocyst frequency had been achieved in the control culture (Fig. 6). The effect on maturation continued to decline until addition of $\mathrm{AT}$ at $25 \mathrm{~h}$ after ammonium deprivation permitted the formation of the same proheterocyst and mature heterocyst frequencies as the control.

\section{Discussion}

The effects of AT on heterocyst frequency and pattern described here are in essential agreement with those reported for several Anabaena species (Mitchison \&

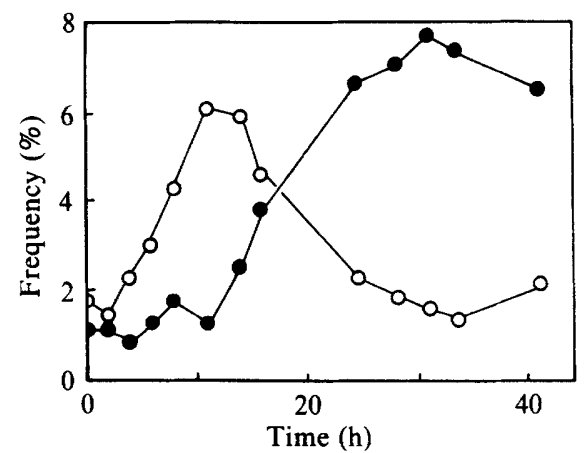

Fig. 6. Time course of heterocyst development in an untreated control culture for the experiment illustrated in Fig. 5. Proheterocyst $(O)$ and heterocyst (O) frequencies were estimated at the times indicated.

Wilcox, 1973; Bothe \& Eisbrenner, 1977; Rogerson, 1979; Kumar \& Kumar, 1980). Under the conditions employed in this work, the most frequent multiple heterocysts resulting from incubation with AT were doubles. We have previously observed the formation of double heterocysts in $\boldsymbol{A}$. cylindrica following incubation at high light intensities (Adams \& Carr, 1981 b). This results from an increase in the frequency of symmetrical cell divisions during incubation at the higher light intensity. Mitchison \& Wilcox (1972) have shown that cell division in Anabaena is asymmetrical and that heterocysts develop from only the small daughter cell. Following incubation of $A$. cylindrica at high light intensity the frequency of asymmetrical cell divisions decreases and many pairs of identical daughter cells are produced; in some cases both of these daughter cells differentiate, resulting in the formation of double heterocysts (Adams \& Carr, 1981b). To investigate the possibility that such a mechanism might explain the preponderance of double heterocysts induced by AT, I examined the symmetry of cell division under various growth conditions following AT addition. In no case was there any evidence that AT affected the symmetry of cell division. It should also be noted that growth at high light intensity has little effect on heterocyst spacing, the number of vegetative cells between heterocysts (the interheterocyst interval) decreasing only very slightly following incubation at high light (Adams \& Carr, 1981 b). AT, however, induces a considerable decrease in interheterocyst intervals and clearly, therefore, reduces the size of heterocyst inhibitory zones (see Mitchison \& Wilcox, 1973; Wilcox et al., 1973; Rogerson, 1979).

How might AT influence heterocyst pattern? It is clear that the presence of the analogue reduces the inhibitory zones around proheterocysts and heterocysts, and that this effect increases with the period of incubation. This is reflected in the ability of heterocysts to develop ever closer to one another the longer that the filaments have been incubated in the presence of AT (Figs 7 and 8). 


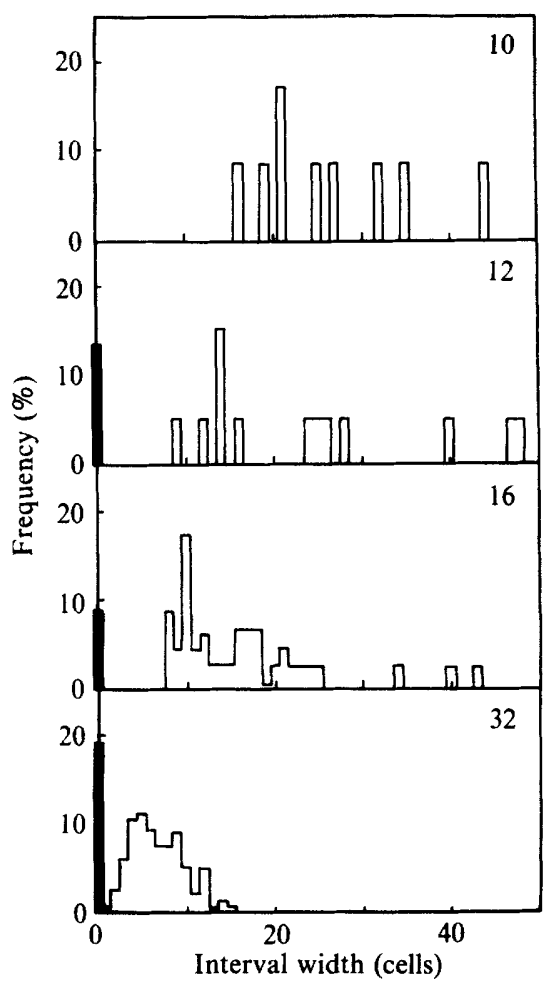

Fig. 7. Effect of AT on interheterocyst intervals in A. cylindrica. The histograms illustrate the range and frequency of interheterocyst interval widths in four samples taken, following ammonium deprivation, from the culture shown in Fig. 1. In this figure and in Fig. 8 an interheterocyst interval width is defined as the number of vegetative cells between a pair of heterocysts or proheterocysts. The number in the top right-hand corner of each histogram indicates the time (h) at which the sample was counted in relation to ammonium removal and AT addition $(0 \mathrm{~h})$. The filled blocks indicate zero interval widths (i.e. adjacent proheterocysts or heterocysts).

To examine the way in which AT might affect heterocyst pattern, we must first consider the simplest model to explain heterocyst control and spacing. This is illustrated in Fig. 9, which shows a short section of filament between two heterocysts. The inhibitor, produced by the heterocyst, diffuses through the vegetative cells and is degraded or lost from them at a rate proportional to its concentration, producing a decreasing exponential gradient away from each heterocyst (Wolk, 1975, 1989). A threshold level has been indicated such that a vegetative cell can only differentiate if the intracellular concentration of inhibitor falls below this threshold. In a short interval no cell will be below the threshold (Fig. 9a), but as cell division increases the interval some cells at the centre will fall below the threshold (Fig. 9b) and it is from these that the next heterocyst will develop. This model seems to adequately explain the development of new heterocysts in a growing culture and the way in which the regular spacing is maintained.

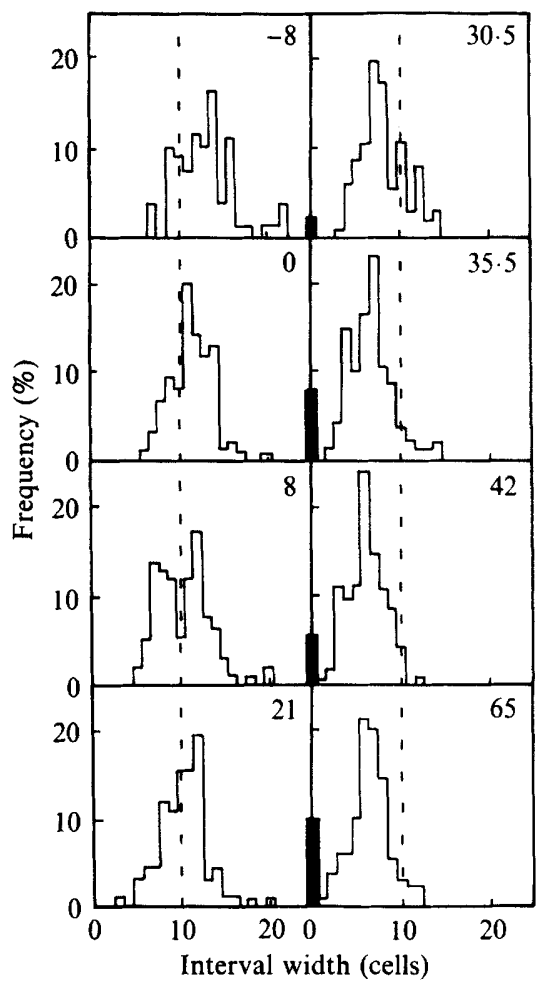

Fig. 8. Effect of AT on interheterocyst intervals in dinitrogen-fixing $A$. cylindrica. The histograms illustrate the range and frequency of interheterocyst interval widths in eight samples from the dinitrogenfixing culture shown in Fig. 2. The number in the top right hand corner of each histogram indicates the time (h) at which the sample was counted in relation to AT addition $(0 \mathrm{~h})$. The vertical dashed lines are to provide a reference point. The filled blocks indicate zero interval widths (i.e. adjacent proheterocysts or heterocysts).

Since the effect of incubation with AT is to reduce the size of inhibitory zones and permit new heterocysts to develop closer to existing ones, we can consider that it reduces, either directly or indirectly, the effective concentration of inhibitor in vegetative cells. Thus, if the concentration is halved in each cell, the new gradient will be as illustrated by the open circles in Fig. $9(b)$. This results in a greater 'below-threshold' region (indicated by the arrowed brackets in Fig. $9 b$ ) and allows new heterocysts to form closer to existing ones than was previously possible. Prolonged incubation with AT will further decrease inhibitor concentration. Thus, the longer the incubation period with AT, the closer to existing heterocysts can new heterocysts develop. This model correlates well with the observed gradual decrease in interval widths in dinitrogen-fixing cultures incubated with AT (Fig. 8).

As interval widths become smaller and smaller there will be a point when they reach one cell. Any subsequent decrease will lead to the formation of a double heterocyst. However, this is not precisely how it happens in growing 


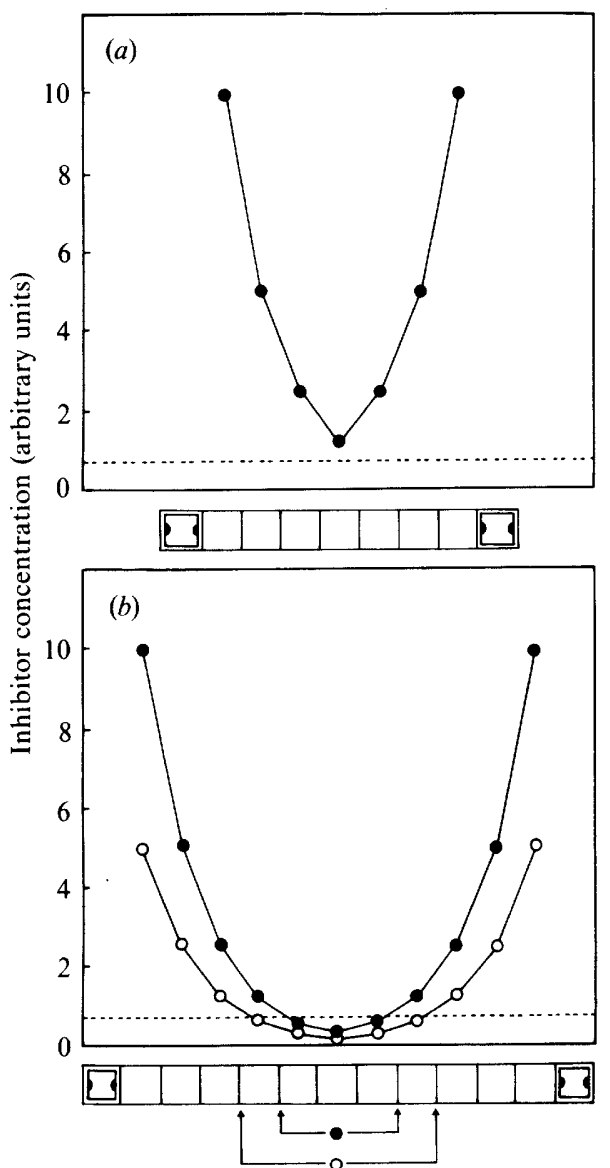

Fig. 9. Diagram illustrating the possible effects of AT on the distribution of a hypothetical inhibitor of heterocyst development. (a) A short section of filament, bounded by two mature heterocysts and containing seven vegetative cells, is illustrated. Each point (O) represents the concentration, within the vegetative cell, of a hypothetical heterocyst-derived inhibitor of differentiation. The dashed line indicates the threshold concentration of inhibitor below which differentiation can occur. $(b)$ Vegetative cell division has increased the number of cells between the two heterocysts to eleven. The concentration of heterocyst-derived inhibitor is illustrated both before (O) and after $(O)$ incubation of the culture with AT, which causes an increase in the number of cells in the 'below threshold' region (arrows).

cultures, since the minimum interval widths when double heterocysts first develop are nine cells in a culture treated with AT immediately following fixed nitrogen removal (Fig. 7) and three cells in a dinitrogen-fixing culture to which AT was added (Fig. 8). Thus, double heterocysts develop long before intervals have decreased to one cell. How can this be explained?

Since it is known that in at least some Anabaena species cell division is asymmetric (Mitchison \& Wilcox, 1972) and that in Anabaena catenula heterocysts develop from only the smaller daughter cell, there is clearly a competitive process which prevents the larger daughter from differentiating (Wilcox et al., 1973). A modification of the inhibitor/diffusion model can provide an explanation of not only the way in which daughter cells compete with one another and how AT might influence this competition, but also why proheterocysts do not inhibit their own development. This model requires that vegetative cells produce, constitutively, an inactive inhibitor of differentiation (I) which can be activated by a co-inhibitor $(\mathrm{H})$ derived either from developing or mature heterocysts, or from high concentrations of available fixed nitrogen (Adams, 1978). Hence, in a culture grown in the presence of ammonium, the inhibitor will be active in all cells and none will differentiate. In a dinitrogen-fixing culture, cells adjacent to heterocysts or proheterocysts will be prevented from differentiating because of the heterocyst-derived co-inhibitor. Thus, inhibitory zones are derived from the interaction of $\mathrm{I}$ and $\mathrm{H}$ to produce active inhibitor, IH. Rogerson (1979) proposed a similar idea in which the heterocyst inhibitor was also produced by vegetative cells and its active concentration was regulated by the ammonium supply.

When two recently formed daughter cells have begun development (although at a stage long before any morphological change is visible by light microscopy) they must contain below-threshold concentrations of $\mathrm{H}$, such that the concentration of $\mathrm{IH}$ is also below threshold. Since these cells are about to begin synthesizing $\mathbf{H}$ to enable them to generate their own inhibitory zones, it is important that they not only cease synthesis of I, but also remove any remaining inactive inhibitor to avoid inhibiting their own development. This might be achieved, for example, by natural decay or by the action of a specific enzyme to degrade I. The very early stages of heterocyst development are, therefore, characterized by a steady decline in the intracellular concentration of I and an increase in the intracellular concentration of $\mathrm{H}$. It is the relative rates of these two changes which decide whether a cell will continue to differentiate or will return to vegetative growth. Thus, if I falls below threshold before $\mathrm{H}$ reaches threshold, the cell will continue to differentiate.

What might the chemical nature of the inhibitor be? One suggestion is glutamine produced either by dinitrogen-fixing heterocysts, or by developing heterocysts due to proteolysis induced by nitrogen starvation (see Wolk, 1989). However, although incubation of cyanobacteria with AT can cause changes in the intracellular pools of amino acids, including glutamine (Chen et al., 1987), there is increasing evidence against the involvement of glutamine as an inhibitor of heterocyst development (Thiel \& Leone, 1986; Chen et al., 1987; Thiel, 1990). An alternative is that AT effects changes in heterocyst pattern by its incorporation into a protein which is involved in the regulation of heterocyst development (Mitchison \& Wilcox, 1973; Adams, 1978; Bottomley et al., 1980). Such a protein might be a repressor which 
regulates gene expression by binding to DNA and the activity of which is adversely affected by incorporation of AT into the molecule (Adams 1978; Bottomley et al., 1980). In the model presented here it could be argued that AT might affect either $\mathrm{I}$ or $\mathrm{H}$ since either would reduce the activity of the complex. With this in mind we can attempt to explain why only small daughter cells develop into heterocysts (Mitchison \& Wilcox, 1972).

At cell division I must be partitioned between daughter cells and it can be assumed that this occurs in proportion to cell volume, so that the smaller daughter receives fewer molecules of $I$, although the concentration per unit cell volume is the same as for the larger daughter. If IH functions by a specific interaction with DNA, its concentration per DNA-binding site will be smaller in the smaller daughter cell and greater in the larger cell. The threshold can now be seen as a specific ratio of $\mathrm{IH}$ to DNA-binding sites. This means that the smaller daughter cell begins life with a lower likelihood of inhibition since I will always fall below threshold sooner than in the large daughter.

This model can explain the formation of double heterocysts following exposure to high light intensity (Adams \& Carr, 1981 b). Because many more daughter cells are equal in size, they possess equal amounts of I and their ability to compete will be diminished, so that in many cases both will develop into heterocysts. Thus, the effect of high light is an indirect one on the symmetry of cell division and it is this which affects the differentiation of cells.

The effect of AT is clearly different, in that no influence on the symmetry of cell division is observed. It must, therefore, have some effect on I or H. I is already present in vegetative cells and developing proheterocysts, and indeed is diminishing in the latter, so it seems unlikely that AT will have any influence on I under these circumstances. It seems more likely that AT will affect $\mathrm{H}$, which will be particularly susceptible since it is being synthesized de novo. Thus it can be surmised that AT reduces the rate of increase in the concentration of $\mathrm{H}$ in these early proheterocysts, allowing more time for I to fall below threshold and decreasing the likelihood of either cell becoming inhibited.

Previous attempts to explain the control of heterocyst development and spacing have assumed that developing or mature heterocysts are the source of the inhibitor which prevents adjacent cells from differentiating. This poses the question: why don't these cells always inhibit their own development? Wilcox et al. (1973) attempted to explain this by saying that as a proheterocyst developed, it not only produced more diffusible inhibitor, but also raised the threshold at which its own development could be inhibited. Thus the cell would continue to differentiate unless there was a sudden increase in inhibitor levels caused, for example, by another heterocyst in close proximity.

The model presented here avoids the problem of selfinhibition by assuming that developing heterocysts switch off production of the inhibitor immediately after they begin to differentiate. The concentration of I will then diminish, either by natural decay or degradation by a specific enzyme. Before I falls below threshold, the cell can still become inhibited if $\mathrm{H}$ reaches threshold. However, the cell is committed once I has fallen below the threshold level since no amount of $\mathrm{H}$ can then prevent it from completing differentiation.

\section{References}

ADAMS, D. G. (1978). Differentiation, pattern control and macromolecule synthesis in the blue-green alga Anabaena cylindrica. PhD thesis, University of Liverpool.

ADAMS, D. G. \& CARR, N. G. (1981a). The developmental biology of heterocyst and akinete formation in cyanobacteria. CRC Critical Reviews in Microbiology 9, 45-100.

ADAMS, D. G. \& CARR, N. G. (1981 b). Heterocyst differentiation and cell division in the cyanobacterium Anabaena cylindrica: effect of high light intensity. Journal of Cell Science 49, 341-352.

ADAMS, D. G. \& CARR, N. G. (1989). Control of heterocyst development in the cyanobacterium Anabaena cylindrica. Journal of General Microbiology 135, 839-849.

Allen, M. B. \& ARNON, D. I. (1955). Studies on nitrogen-fixing bluegreen algae. Plant Physiology 30, 366-372.

Bothe, H. \& Eisbrenner, G. (1977). Effect of 7-azatryptophan on nitrogen fixation and heterocyst formation in the blue-green alga Anabaena cylindrica. Biochemie und Physiologie der Pflanzen 171, 323-332.

Bottomley, P . J., Van BaAlen, C. \& Tabita, F. R. (1980). Heterocyst differentiation and tryptophan metabolism in the cyanobacterium Anabaena sp. CA. Archives of Biochemistry and Biophysics 203, 204-213.

Chen, C., VAN BAalen, C. \& Tabita, F. R. (1987). Nitrogen starvation mediated by DL-7-azatryptophan in the cyanobacterium Anabaena sp. strain CA. Journal of Bacteriology 169, 1107-1113.

FoGG, G. E. (1944). Growth and heterocyst production in Anabaena cylindrica Lemm. New Phytologist 43, 164-175.

FoGG, G. E. (1949) Growth and heterocyst production in Anabaena cylindrica Lemm. II. In relation to carbon and nitrogen metabolism. Annals of Botany NS 13, 241-259.

Kumar, A. \& KumaR, H. D. (1980). Differential effects of amino acid analogs on growth and heterocyst differentiation in two nitrogenfixing blue-green algae. Current Microbiology 3, 213-218.

Mrrchison. G. J. \& Wilcox, M. (1972). Rule governing cell division in Anabaena. Nature, London 239, 110-111.

Mitchison. G. J. \& Wilcox, M. (1973). Alteration in heterocyst pattern of Anabaena produced by 7-azatryptophan. Nature New Biology 246, 229-233.

ROGERSON, A. C. (1979). Modifiers of heterocyst repression and spacing and formation of heterocysts without nitrogenase in the cyanobacterium Anabaena variabilis. Journal of Bacteriology 140, 213-219.

Thiel, T. (1990). Protein turnover and heterocyst differentiation in the cyanobacterium Anabaena variabilis. Journal of Phycology 26, 50-54.

ThIEL, T. \& LEONE, M. (1986). Effect of glutamine on growth and heterocyst differentiation in the cyanobacterium Anabaena variabilis. Journal of Bacteriology 168, 769-774.

Wilcox, M., Mitchison, G. J. \& Smith, R. J. (1973). Pattern formation in the blue-green alga Anabaena. II. Controlled proheterocyst regression. Journal of Cell Science 13, 637-649. 
Wolk, C. P. (1967). Physiological basis of the pattern of vegetative growth of a blue-green alga. Proceedings of the National Academy of Sciences of the United States of America 57, 1246-1251.

Wolk, C. P. (1975). Differentiation and pattern formation in filamentous blue-green algae. In Spores VI, pp. 85-96. Edited by $P$.
Gerhardt, R. N. Costilow \& H. L. Sadoff. Washington, DC: American Society for Microbiology.

Wolk, C. P. (1989). Alternative models for the development of the pattern of spaced heterocysts in Anabaena (Cyanophyta). Plant Systematics and Evolution 164, 27-31. 